\title{
Spontaneous rupture of umbilical hernia in an adult with evisceration of small bowel: a case report
}

Yugal Limbu, Manish Pokhrel, Tanka Prasad Bohara, Mukund Raj Joshi

\begin{abstract}
Spontaneous rupture of umbilical hernia in an adult patient is a rare presentation. We present a case of a 43-year old male patient with long standing history of umbilical hernia who presented with sudden spontaneous rupture of the hernia with evisceration of the small bowel. The authors would like to highlight this rare complication of umbilical hernia and its management.
\end{abstract}

Keywords: Evisceration; Spontaneous rupture; Umbilical Hernia.

\section{Author affiliations:}

Department of GI and General Surgery, Kathmandu Medical College Teaching Hospital, Sinamangal, Kathmandu, Nepal.

\section{Correspondence:}

Dr. Yugal Limbu, Department of GI and General Surgery, Kathmandu Medical College Teaching Hospital, Sinamangal, Kathmandu, Nepal.

Email: yugallimbu21@gmail.com ORCID: https://orcid.org/0000-0001-73765926

\section{Copyright information:}

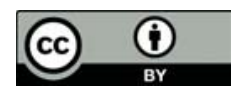

How to cite this article:

Limbu Y, Pokhrel M, Bohara TP, Joshi MR. Spontaneous rupture of umbilical hernia in an adult with evisceration of small bowel: a case report. J Soc Surg Nep. 2020 Dec;23(2):59-62.

DOI:

https://doi.org/10.3126/jssn.v23i2.35842

\section{Introduction}

There are multiple areas of potential weakness in the anterior abdominal wall such as the deep and superficial inguinal rings, Hesselbach's triangle, the femoral ring and so on. Among these potentially weak areas, the umbilicus is one where the continuity of the linea alba is interrupted. ${ }^{1}$ Umbilical hernia is a primary ventral hernia located in the center of the umbilical ring. ${ }^{2}$ In adults, umbilical hernias are most often acquired due to increased intra-abdominal pressure brought on by obesity, abdominal distension, ascites, or pregnancy. ${ }^{3}$

In adults, umbilical hernias are more common in females than in men, however in men, they have greater propensity to get incarcerated. The omentum or preperitoneal fat are the most common content of the umbilical hernia sac. ${ }^{4}$ Umbilical hernia is not uncommon in adults and it is diagnosed in up to 23 percent of individuals screened by physical exam or ultrasound. ${ }^{5}$ Nevertheless spontaneous rupture of umbilical hernia with evisceration of small bowel is a rare presentation. ${ }^{6}$

\section{Case Report}

A 43-year-old woman presented in the emergency department (ED) with two hours of central abdominal discomfort following a bout of cough after which she noticed protrusion of bowel through a defect in the anterior abdominal wall. The patient had a history of lump in the umbilical region for the past five years which had been gradually increasing in size. Initially the lump used to reduce spontaneously but for the past one year she could not reduce the swelling. She had been using some oral ayurvedic medicine along with compression of the lump with a hot 
water bag for the past three months in an effort to reduce the swelling. She mentioned that she used to put the hot water bag over the swelling before going to bed for around 15 minutes every night for the past three months. She was a known case of hypertension under some undocumented oral ayurvedic medication. She did not smoke or drink alcohol. She mentioned that she gained weight of around 10 kilograms in the past one year. Before the evisceration, she had no abdominal pain, distention, nausea, vomiting and was passing stool and flatus regularly. She denied trauma to the umbilical area or recent abdominal surgery or instrumentation. However, she had noticed some ulceration over the surface of the lump for the past two months which was gradually increasing in size with some redness around the surrounding skin.

At the ED she had a blood pressure of $180 / 100 \mathrm{mmHg}$, heart rate of 108 beats/min, respiratory rate of 22 breaths/ min, oxygen saturation of $92 \%$ in room air, and temperature of $97^{\circ} \mathrm{F}$. The patient was alert and fully oriented, though anxious. Her height was $160 \mathrm{cms}$ and she weighed 105 kilograms equating to a Body mass index (BMI) of 41.0. She did not have scleral icterus, asterixis, or tremor. The patient had the protruded bowel covered with a clean towel at presentation in the ED. The towel was removed and she was noted to have approximately $50 \mathrm{~cm}$ of small bowel protruding from the tip of a lump in the umbilical region (Figure 1). The protruding bowel was pink and well perfused, without signs of ischemia or necrosis. No visible fluid was leaking through the umbilical defect. The skin surrounding the defect was superficially ulcerated with mild erythema. Rest of the abdomen was soft and nontender with no scar marks.

Laboratory studies revealed a white blood cell count of $11,900 /$ microliter and rest of the routine tests were within normal limit. A moist, sterile dressing was placed over the eviscerated bowel. Patient was given IV fluids and injection Ceftriaxone (1 gm) in the ED before the patient was taken to the operating room.

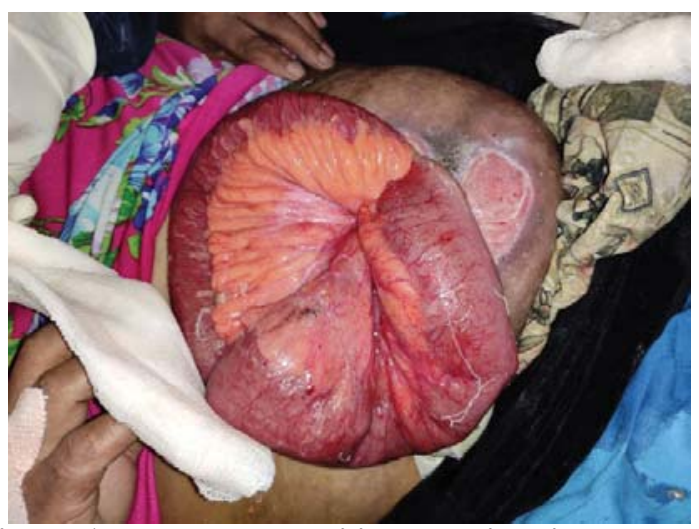

Figure 1. Ruptured umbilical hernia with protruded bowel (Patient's head end towards the top of the image)

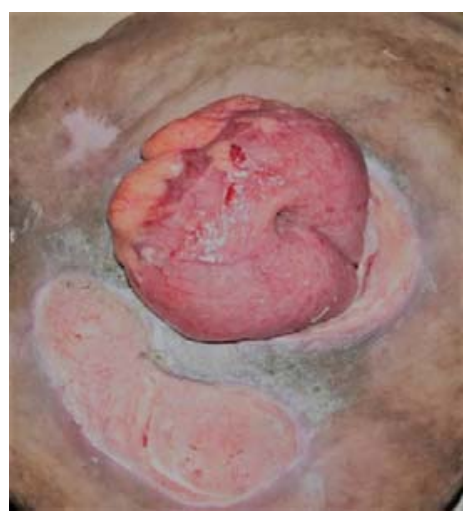

Figure 2. Hernia after partial reduction

In the operating room, after the patient was given general anesthesia, the eviscerated bowel was reassessed and was irrigated with sterile saline. Then the bowel was partially replaced in the abdomen (Figure 2) to facilitate ease of incision over the swelling. An incision of approximately $10 \mathrm{~cm}$ long was carried out in the cranio-caudal direction starting from the skin defect and the neck of the hernia was identified in the fascial layer which was around $4 \mathrm{cms}$ in diameter. A small leaf of omentum and bowel was adhered to the neck which was carefully separated using sharp dissection. Once the adhesiolysis was complete, the hernia was completely reduced and the adjacent peritoneal cavity was then irrigated with warm saline. In view of possibility of contamination, mesh was not used to close the defect. Intraoperatively, it was noted that the fascial layer could be opposed without tension hence, it was closed primarily with polypropylene no.1 in an interrupted fashion. The thinned out redundant and ulcerated umbilical skin was excised and the incision closed primarily over a negative suction Romovac ${ }^{\mathrm{TM}}$ drain (Figure 3). The patient's hospital course was uneventful and the patient was discharged on the fourth postoperative day with the drain in situ which was draining 30-40 $\mathrm{ml}$ of serosanguinous effluent. On follow up in the OPD, the wound was healthy and the drain was removed on post-operative day seven. There were no abdominal complications or recurrence of hernia during a four month follow up period (Figure 4).

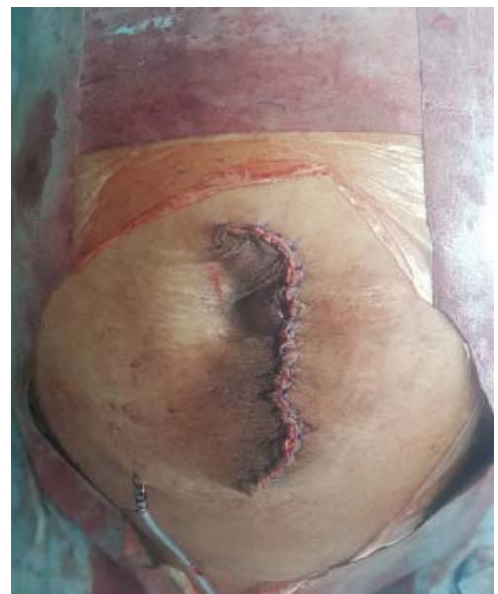

Figure 3. Following abdominal closure 


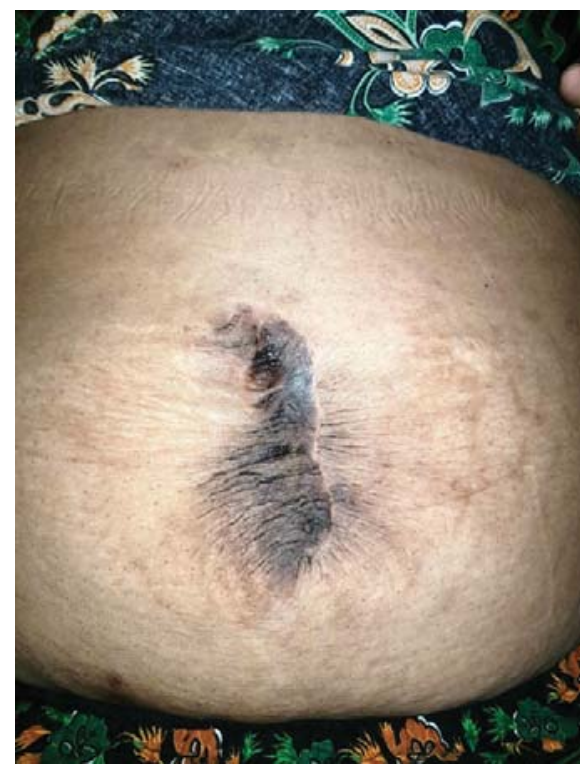

Figure 4. Wound at four month follow up

\section{Discussion}

There have been few reports of rupture of umbilical hernia in the setting of ascites in the patients which have been termed as Flood Syndrome. ${ }^{7-10}$ However spontaneous rupture of umbilical hernia in the absence of underlying ascites is extremely rare. The incidence of hernias is increased in patients with alcoholic liver disease with ascites. ${ }^{11}$ The first reported case of spontaneous rupture of an umbilical hernia from ascites was reported by Mixter in $1901 .^{3}$ The precipitating factors for rupture can include local trauma and a sudden increase in intra-abdominal pressure, such as coughing, vomiting or esophagoscopy. ${ }^{12}$ In our case, the possible risk factors which played a role for spontaneous rupture are obesity, the repeated compression of the lump with hot water bags and coughing.

\section{References}

1. Russel RCG, Williams NS, Bulstrode CJK, (eds.). Bailey \& Love's Short Practise of Surgery. 25 edition. London: Taylor and Francis; 2008.

2. Henriksen NA, Montgomery A, Kaufmann R, et al. Guidelines for treatment of umbilical and epigastric hernias from the European Hernia Society and Americas Hernia Society. Br J Surg. 2020 Feb;107(3):171-190.

3. Johnnson JT: Ruptured umbilical hernia. Trans South Surg Assoc 1901, 14:257-268.

4. Kokotovic D, Sjølander H, Gögenur I, Helgstrand F. Watchful waiting as a treatment strategy for patients with a ventral hernia appears to be safe. Hernia. 2016 Apr;20(2):281-7.

5. Bedewi MA, El-Sharkawy MS, Al Boukai AA, AlNakshabandi N. Prevalence of adult paraumbilical
Dynamic adaptive changes take place in abdominal musculature and fascia in response to a chronically elevated intra-abdominal pressure. These adaptative changes help to maintain the normal functioning of the intra-abdominal viscera. ${ }^{13,14}$ Studies have shown that the adaptations are mainly in the form of changes in the muscular components of the abdominal cavity. ${ }^{15}$ Similarly the diaphragm also has the ability to adapt when subjected to conditions of increasing intra-abdominal pressure. ${ }^{16}$ However, it is plausible that a long-standing hernia when subjected to repeated hot compressions may lead to thermal injury leading to necrosis of the overlying tissue. This when compounded by sudden increase in intraabdominal pressure as in coughing may have resulted in the rupture of the hernia leading to evisceration of the bowel as seen in our case.

Although the defect was large, in view of possibility of contamination we opted not to use a mesh to close the defect. Additionally, as it was noted that the margins of the fascial defect could be opposed together without tension, primary repair was justified in this case, also evidenced by the fact that there were no postoperative complications related to raised intra-abdominal pressure.

\section{Conclusion}

Umbilical hernia, albeit a benign disease, may present in a complicated manner which if not treated promptly can be life threatening. This article further highlights the importance of timely surgical management of umbilical hernias.

\section{Consent:}

Written informed consent was obtained from the patient for publication of this case report and any accompanying images.

hernia. Assessment by high-resolution sonography: a hospital-based study. Hernia. 2012 Feb;16(1):5962.

6. Choo EK, McElroy S. Spontaneous Bowel Evisceration in a Patient with Alcoholic Cirrhosis and an Umbilical Hernia. J Emerg Med. 2008 Jan;34(1):41-3.

7. Colbran R, Smith A, Melloy A, Iyer R. Spontaneous umbilical hernia rupture with omental evisceration and Flood syndrome. Int Surg J. 2019;6(10):3830-3.

8. Liu GF, Srinivasan A, Mutnuri S, Yerramadha MR, Agraharkar M. Acute Abdomen From Umbilical Hernia Rupture to Flood Syndrome: A Case Report and Review of Literature. J Med Cases. 2019;10(10):309-11.

9. DeLuca IJ, Grossman ME. Flood syndrome. JAAD Case Rep. 2014 Sep 28;1(1):5-6.

10. Nguyen ET, Tudtud-Hans LA. Flood Syndrome. 
Spontaneous Umbilical Hernia Rupture Leaking Ascitic Fluid-A Case Report. Perm J. 2017;21:16152.

11. Chapman CB, Snell AM, Roundtree LG. Decompensated portal cirrhosis. JAMA 1931. 97:237-244.

12. Good DW, Royds JE, Smith MJ, Neary PC, Eguare E. Umbilical hernia rupture with evisceration of omentum from massive ascites: A case report. J Med Case Rep. 2011 May 3;5:170.

13. Gilleard WL, Brown JM. Structure and function of the abdominal muscles in primigravid subjects during pregnancy and the immediate postbirth period. Phys Ther. 1996 Jul;76(7):750-62.

14. Lalatta Costerbosa G, Barazzoni AM, Lucchi ML, Bortolami R: Histochemical types and sizes of fibres in the rectus abdominis muscle of guinea pig: adaptive response to pregnancy. Anat Rec. 1987 Jan;217(1):23-9.

15. Papavramidis TS, Duros V, Michalopoulos A, Papadopoulos VN, Paramythiotis D, Harlaftis $\mathrm{N}$. Intra-abdominal pressure alterations after large pseudocyst transcutaneous drainage. BMC Gastroenterol. 2009; 9:42.

16. Kotidis EV, Papavramidis TS, Ioannidis K, Cheva A, Lazou T, Michalopoulos $\mathrm{N}$ et al. The effect of chronically increased intra- abdomial pressure on rectus abdominis muscle histology an experimental study on rabbits. J Surg Res. 2011 Dec;171(2):60914. 